\title{
Effect of co-administration of atelocollagen and hyaluronic acid on rotator cuff healing
}

\author{
Jeung Yeol Jeong ${ }^{1}$, Eun Kyung Khil ${ }^{2}$, Tae Soung Kim ${ }^{1}$, Young Woo Kim ${ }^{1}$ \\ ${ }^{1}$ Department of Orthopedic Surgery, Hallym University Dongtan Sacred Heart Hospital, Medical College of Hallym University, Hwaseong, Korea \\ ${ }^{2}$ Department of Radiology, Hallym University Dongtan Sacred Heart Hospital, Medical College of Hallym University, Hwaseong, Korea
}

Background: This study aimed to evaluate the co-administration effect of atelocollagen combined with hyaluronic acid (HA) injections for treatment of full-thickness rotator cuff tear (RCT).

Methods: Eighty patients who underwent arthroscopic rotator cuff repair for full-thickness RCT from March 2018 to November 2019 were enrolled. The patients were randomly allocated to the following groups: combined atelocollagen and HA injection (group I, n=28), only HA injection (group II, $\mathrm{n}=26$ ), and no injection (group III, $\mathrm{n}=26$ ). Clinical outcomes were assessed at 3, 6, and 12 months after surgery using the American Shoulder and Elbow Surgeons score, visual analog scale pain score, functional scores (pain visual analog scale, function visual analog score), and range of motion. Magnetic resonance imaging was performed 12 months after surgery to evaluate rotator cuff integrity. Results: Preoperative demographic data and postoperative clinical outcomes did not differ significantly among the three groups ( $>0.05$ ). However, in group I, the number of steroid injections after surgery was significantly lower than that in the other groups ( $\mathrm{p}=0.011)$. The retear rate on follow-up magnetic resonance imaging was significantly higher in group II $(9.5 \%, \mathrm{n}=2)$ and group III (13.6\%, $\mathrm{n}=3)$ than in group I (0\%) ( $\mathrm{p}=0.021)$.

Conclusions: Co-administration of atelocollagen and HA improves healing of the rotator cuff and increases the integrity of the rotator cuff repair site. This study provides encouraging evidence for use of combined atelocollagen-HA injections to treat patients with full-thickness RCT.

Keywords: Shoulder; Rotator cuff; Full-thickness tear; Atelocollagen; Hyaluronic acid

\section{INTRODUCTION}

Rotator cuff tear (RCT) is a highly prevalent condition (approximately 20\%) in the general population and causes significant impairment such as shoulder pain and dysfunction [1,2]. The incidence of RCT increases with age. Owing to recent advances in imaging and surgical techniques, rotator cuff repair generally yields satisfactory clinical outcomes $[3,4]$. However, postoperative retear is a serious problem, with an incidence between $34.2 \%$ and $40 \%$ [5]. Postoperative retear of repaired rotator cuff tendons is a challenging problem in orthopedics. To prevent postoperative retear, the effects of various biological agents on tendon-tobone healing have been investigated using animal models [1,6-9].

Received: April 8, $2021 \quad$ Revised: May 22, $2021 \quad$ Accepted: May 23, 2021

Correspondence to: Young Woo Kim

Department of Orthopedic Surgery, Hallym University Dongtan Sacred Heart Hospital, Medical College of Hallym University, 7 Keunjaebong-gil, Hwaseong 18450, Korea

Tel: +82-31-8086-2410, Fax: +82-31-8086-2029, E-mail: ywkimmd@hallym.or.kr, ORCID: https://orcid.org/0000-0002-7845-6716

Financial support: None.

Conflict of interest: None.

Copyright@ 2021 Korean Shoulder and Elbow Society.

This is an Open Access article distributed under the terms of the Creative Commons Attribution Non-Commercial License (http://creativecommons.org/licenses/by-nc/4.0/) which permits unrestricted non-commercial use, distribution, and reproduction in any medium, provided the original work is properly cited. 
Collagen is abundantly distributed as a structural and biologically active component of tissues, including skin, bones, and cartilage, especially in mammals, including humans (up to $25 \%$ of total protein) $[7,10]$. Collagen fibers play an important role in transmitting muscle power, dispersing energy, and preventing mechanical failure in connective tissues [11]. Atelocollagen obtained by protease or pepsin treatment can be used in humans due to its low immunogenicity; no telopeptides show collagen antigenicity [12]. In several animal models, administration of atelocollagen to the site of rotator cuff tendon tear has led from early progression to better tendon healing and remodeling stages based on immunohistochemistry or histopathological analyses [6,7]. Kim et al. [13] reported that atelocollagen injection could improve the functional outcome and integrity of tendons in human RCT.

Hyaluronic acid (HA) injection is used widely in patients with rotator cuff disease due to its anti-inflammatory and adhesion prevention activities [14]. In tendon-to-bone healing, inflammation can contribute to formation of fibrotic scar tissue interfaces rather than remodeling of normal tendon-bone insertion sites [15]. Because of this possibility, tendon-to-bone healing is difficult at the boundary between the tendon and bone in a state of inflammation. HA not only has an anti-inflammatory effect, but also plays an important role in promoting cell differentiation and growth, improving the expression of collagen I in tendon-derived cells, and contributes to many activities promoting tendon and bone healing $[8,16,17]$. Chou et al. [18] reported that HA is effective clinically in treatment of patients with RCT.

As each material targets a specific phase of tendon healing, a mixture of materials targeting different phases might have a synergistic effect. In recent years, some orthopedic fields have reported benefits of such synergistic therapeutic effects [1,19]. However, to date, there are no studies reporting the effect of co-administration of atelocollagen and HA in RCT treatment. Therefore, this study evaluated the efficacy of atelocollagen combined with HA injections versus HA injections alone for treatment of patients with full-thickness RCT. The hypothesis is that, after rotator cuff repair, co-administration of atelocollagen and HA results in better tendon-to-bone healing at the repair site and increases biomechanical strength.

\section{METHODS}

This study was approved by the Institutional Review Board of Hallym University College of Medicine, Dongtan Sacred Heart Hospital (IRB No. 2019-12-012). All patients provided informed consent before participating in this study.

\section{Study Design}

We performed a prospective randomized controlled trial to determine whether the co-administration effects of atelocollagen and HA increased rotator cuff healing and improved clinical results. An independent investigator of the patient information prepared and sealed an opaque envelope containing the group number. Just before surgery, we randomly categorized patients into three groups: atelocollagen with HA group (group I), only HA group (group II), and without atelocollagen and HA group (group III) as the control. The patients were blinded to the treatment they received. We used $3 \mathrm{~mL}$ of atelocollagen (3\% Collapleo; BNC Korea, Daegu, Korea) and 3 mL of HA (Guardix-SP; Genewel, Dongsung Company, Seongnam, Korea) in this study. A total of 110 patients was evaluated for participation in the study. Of these, $30(27 \%)$ were excluded for the following reasons: screen failure $(\mathrm{n}=28)$ and opted not to undergo surgery $(\mathrm{n}=2)$. Finally, a total of 80 patients (group I: 28 patients, group II: 26 patients, and group III: 26 patients) participated in this study. All patients enrolled in this study were operated upon by a single surgeon (JYJ) between March 2018 and November 2019.

\section{Sample Size}

A power analysis was performed with clinical outcomes of pain visual analog scale (PVAS) score, function visual analog score (FVAS), and American Shoulder and Elbow Surgeons (ASES) score [20]. With these parameters, the study required 20 patients per group to achieve a power of 0.80 and a significance level of $5 \%$. The expected dropout rate was $15 \%$.

\section{Patient Selection}

Patients scheduled to undergo arthroscopic rotator cuff repair were enrolled. The inclusion criteria were (1) full-thickness RCT viewed by magnetic resonance imaging (MRI), (2) complete rotator cuff repair (type I repair) covering the entire original footprint of the greater tuberosity [21], and (3) arthroscopic suture-bridge rotator cuff repair [22]. The exclusion criteria were (1) previous rotator cuff repair on the same side, (2) moderate to severe degenerative glenohumeral arthritic changes ( $\geq$ Hamada grade 3), (3) history of rheumatoid arthritis or infectious arthritis, and (4) massive RCT (tear size: $>5 \mathrm{~cm}$ on the basis of the greatest dimension of the tendon tear). The recruitment period began in March 2018 and was completed in November 2019. A total of 80 patients was enrolled in this study. Follow-up loss occurred in six patients in group I, five in group II, and four in group III. Ultimately, 65 patients were available for evaluation at the last follow-up. The flow diagram shows the patient grouping and the structure of the clinical study (Fig. 1). Preoperative de- 


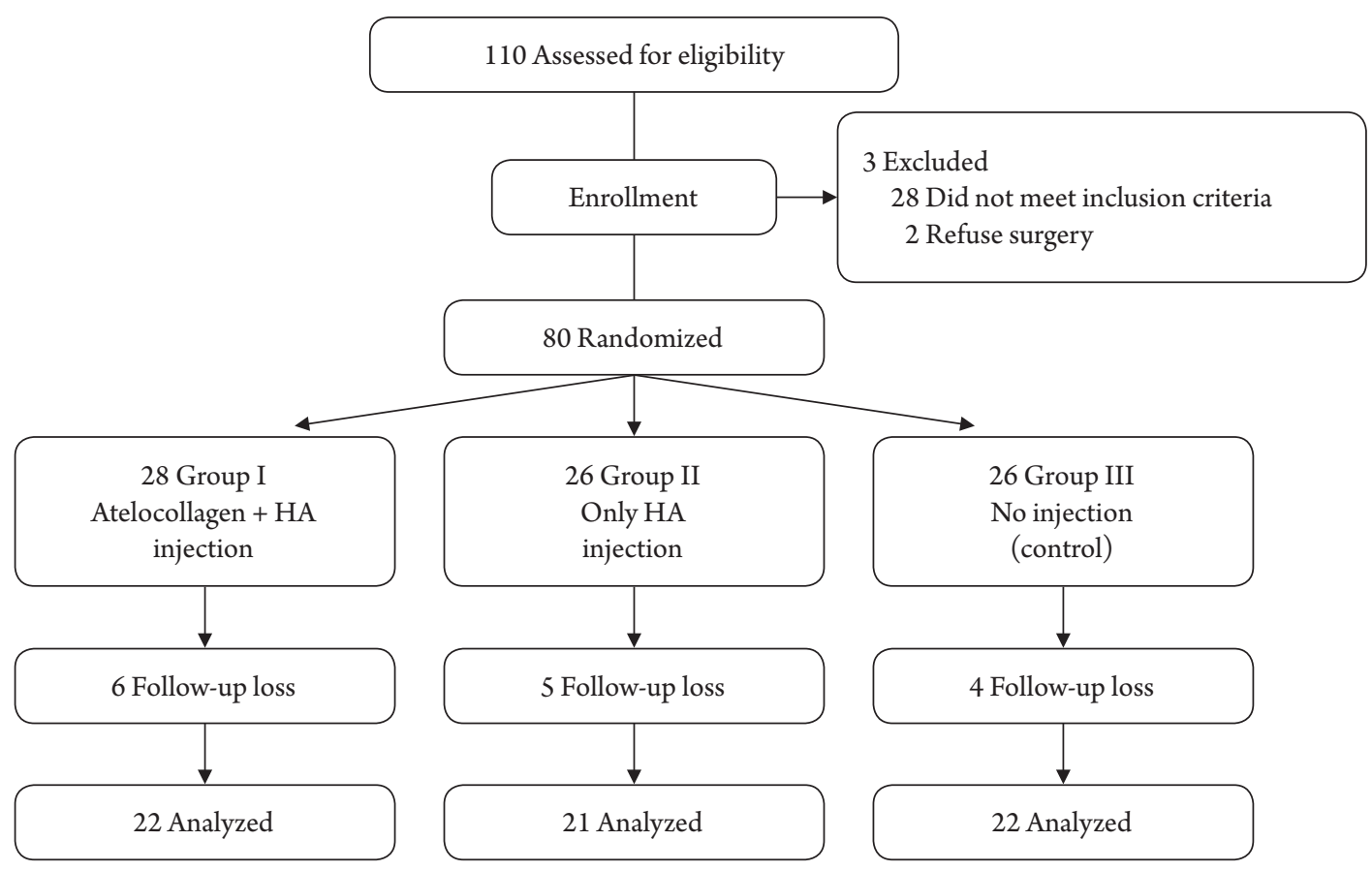

Fig. 1. Consolidated Standards of Reporting Trials (CONSORT) guidelines flowchart. HA: hyaluronic acid.

Table 1. Demographics data

\begin{tabular}{lcccc}
\hline Variable & Group I & Group II & Group III & p-value \\
\hline No. of patients & 22 & 21 & 22 & 0.518 \\
Sex (male:female) & $10: 12$ & $9: 12$ & $12: 10$ & 0.607 \\
Affected shoulder (right:left) & $17: 5$ & $15: 6$ & $14: 8$ & 0.432 \\
Mean age (yr) & $58.8 \pm 5.4(44-77)$ & $60.4 \pm 6.5(48-79)$ & $58.4 \pm 6.5(48-82)$ & 0.167 \\
Mean follow-up duration (mo) & $12.1 \pm 1.5(11-13)$ & $12.3 \pm 1.6(11-14)$ & $11.8 \pm 0.8(11-12)$ & 0.550 \\
\hline
\end{tabular}

Values are presented as number or mean \pm standard deviation (range).

mographic data did not differ among the three groups (Table 1).

\section{Clinical Assessments}

All patients underwent clinical evaluations at 3 months, 6 months, and 1 year after surgery. Clinical outcomes were assessed using preoperative and postoperative PVAS score, FVAS score, and ASES score [20]. A physician assistant also clinically examined the patients using a goniometer to determine active range of motion in forward flexion, abduction, and external rotation with the arm at the side. Internal rotation, based on the location of the highest vertebral level reached by the thumb behind the back, was measured. Shoulder ROM was measured with patients seated. All clinical data were collected by a clinical researcher who was blinded to the current study. At the 3-month follow-up, intra-articular steroid injection was administered to patients with shoulder pain and limitation of active motion in at least two directions (abduction and forward flexion $<120^{\circ}$, external rotation $<30^{\circ}$, or internal rotation $<$ L1) [23].

\section{Radiologic Assessment}

Radiological assessment was completed the day before surgery and 12 months postoperatively using the 3.0-T MRI scanner (Verio; Siemens Medical Solutions, Erlangen, Germany) with an eight-channel shoulder coil. Oblique coronal, oblique sagittal, and transverse views of T2-weighted images on MRI were used to classify postoperative cuff integrity into five categories according to Sugaya et al. [24]. We defined retear as Sugaya classifications types IV and V. Repair integrity was assessed by a blinded musculoskeletal trained radiologist. The radiologist conducted a second assessment on the same images two weeks after the first without knowing the previous results.

\section{Operative Technique}

All surgeries were performed by a single surgeon (JYJ). All pro- 
cedures were performed with patients in the lateral decubitus position under general anesthesia with interscalene block. Diagnostic assessment of the glenohumeral intraarticular joint was performed using a $30^{\circ}$ arthroscope via the posterior portal. The arthroscope was inserted into the subacromial space, and the tear pattern and size of the rotator cuff were observed. The surgery also included subacromial space debridement and release with any additional bone work (acromioplasty) and treatment of biceps tendon if necessary. All rotator cuff repairs were performed according to the double-row transosseous equivalent approach introduced in 2009 [25]. Arthroscopy confirmed complete rotator cuff repair (type I repair) covering the entire original footprint of the greater tuberosity (Fig. 2). After rotator cuff repair, an 18-gauge spinal needle was inserted and positioned on the repaired cuff. After draining water in the subacromial space through negative pressure of the cannula, atelocollagen or HA was injected through a spinal needle in a dry condition (Fig. 3) [26].

\section{Postoperative Rehabilitation}

All patients used an abduction brace for immobilization for 6 weeks after surgery. Passive ROM exercises were started after 6 weeks. Active assisted ROM exercises were started once full passive ROM was recovered. Strengthening exercises were started between 10- and 12-week post-surgery and continued for approximately 3 to 6 months.
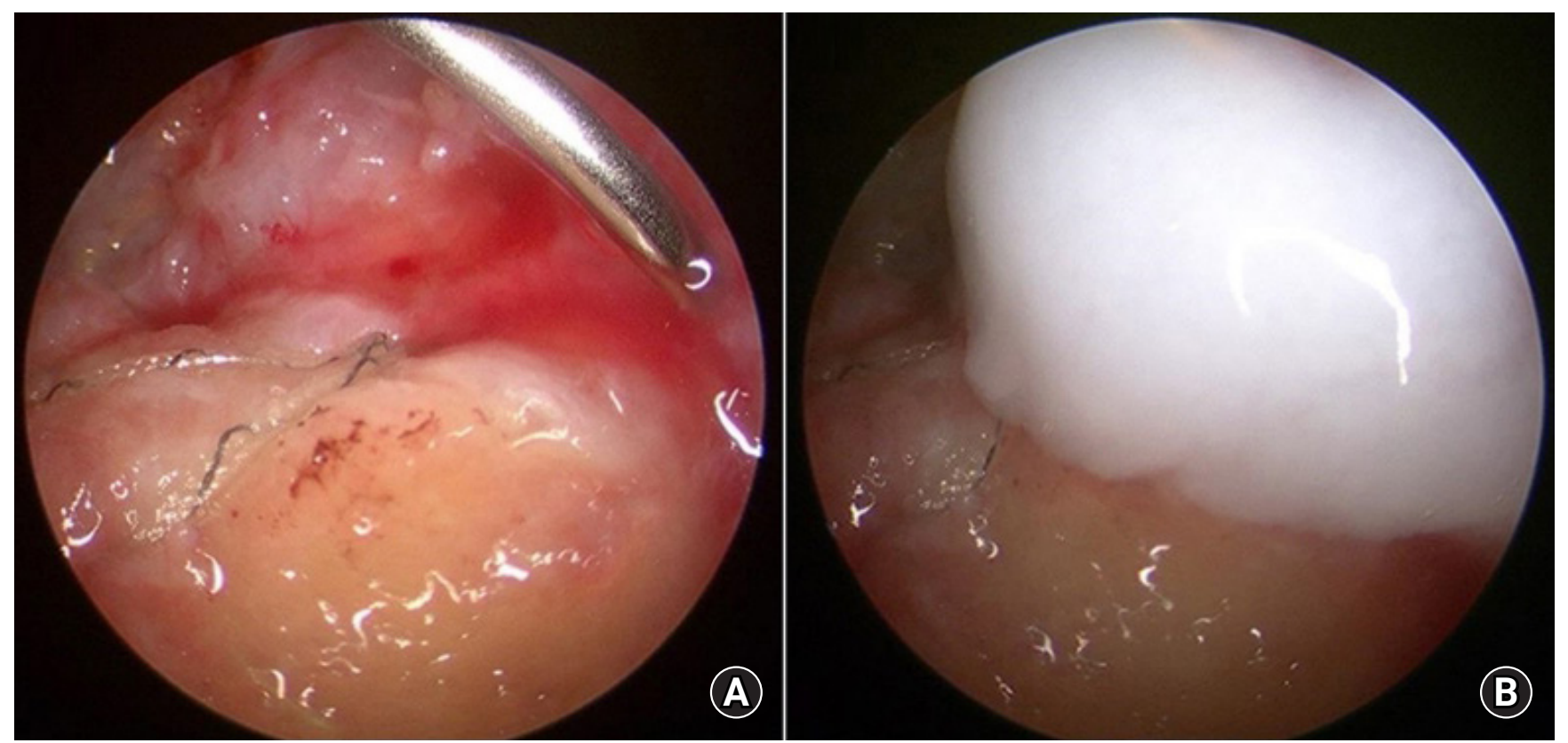

Fig. 2. (A) Arthroscopic photo of an 18-gauge spinal needle positioned on the repaired cuff after repair (left shoulder, posterolateral portal; viewing portal). (B) Arthroscopic photo after injection of atelocollagen (left shoulder).

\section{Statistical Analysis}

Differences in baseline and follow-up assessment among the three treatment groups were tested using one-way analysis of variance. The level of statistical significance was set at $\mathrm{p}<0.05$. Statistical analyses were performed using IBM SPSS ver. 21 (IBM Corp., Armonk, NY, USA) and SAS 9.4 (SAS Institute Inc., Cary, NC,

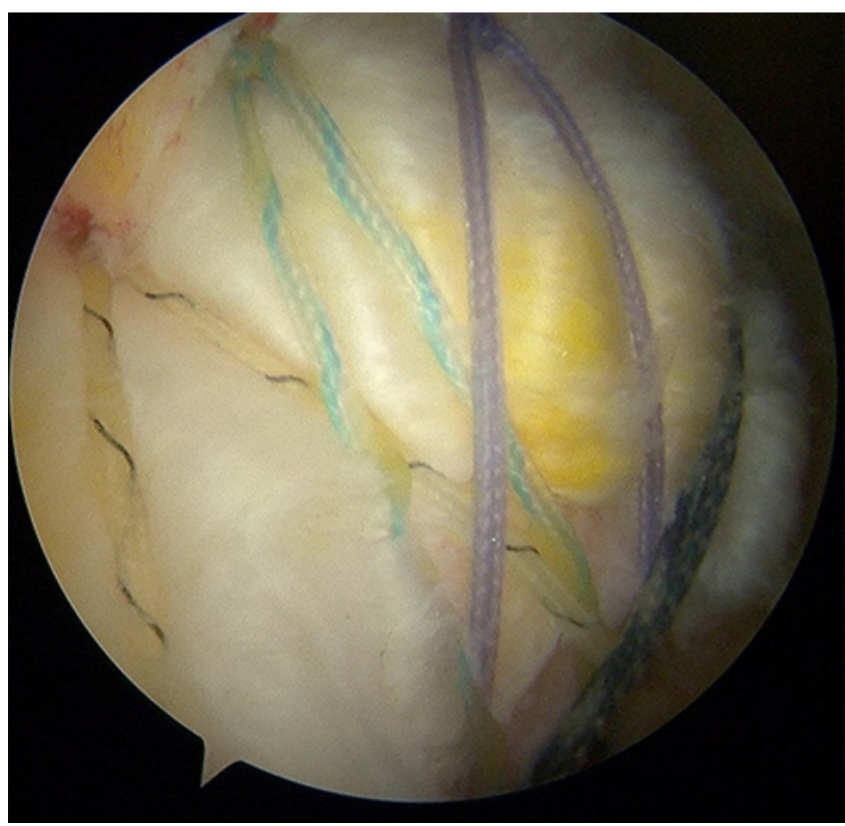

Fig. 3. Arthroscopic photo of rotator cuff tendon repaired with a double-row transosseous technique (right shoulder, posterolateral portal; viewing portal). 
USA). The intraclass correlation coefficient (ICC) was used to assess intra-observer reliability of detection of postoperative cuff integrity. We considered an ICC of 0.7 or higher to indicate good or excellent reliability [27].

\section{RESULTS}

\section{Demographic Data}

Age, sex, and follow-up period were evaluated as demographic factors. No significant differences were observed in the demographic characteristics of the three groups. Table 1 summarizes the epidemiologic factors of the three groups.

\section{Clinical Outcomes}

PVAS, FVAS, ASES scores, and ROM degrees were assessed as clinical factors at 3 months, 6 months, and 1 year postoperatively. There was no significant difference in functional clinical scores among the three groups after surgery (Tables 2-4). However, in most of the clinical outcomes (PVAS, FVAS, ASES scores, and ROM) evaluated at 3 months after surgery, group I (atelocolla- gen $+\mathrm{HA}$ ) showed better results than the other groups (Table 2). Moreover, the number of post-surgery steroid injections was significantly lower in group I (atelocollagen + HA) than in the other groups $(\mathrm{p}=0.011)$ (Table 5).

\section{MRI Outcomes}

The overall mean time between surgery and MRI was 11.7 months (range, 11-13 months). In groups II and III, retear in two and three patients occurred, respectively; however, in group I (atelocollagen+HA), no retear occurred (Table 6). The retear rate was higher in groups II and III, and the difference was statistically significant $(\mathrm{p}=0.021)$.

\section{DISCUSSION}

This study demonstrates that administration of atelocollagen with HA is beneficial for rotator cuff healing. In the patient group administered atelocollagen together with HA, no patient had a retear in the repaired cuff, whereas patients in the other two groups (group II: two patients, group III: three patients) showed

Table 2. Comparison of 3-month postoperative clinical outcomes

\begin{tabular}{lcccc}
\hline Variable & Group I & Group II & Group III & p-value \\
\hline Score & & & & \\
PVAS & $3.91 \pm 1.83(2-9)$ & $4.21 \pm 2.15(2-9)$ & $4.41 \pm 1.85(2-9)$ & 0.071 \\
FVAS & $6.63 \pm 1.90(4-9)$ & $6.50 \pm 1.90(3-9)$ & $6.02 \pm 1.63(4-9)$ & 0.899 \\
$\quad$ ASES & $55.89 \pm 17.40(32-85)$ & $52.86 \pm 15.40(38-80)$ & $54.72 \pm 17.77(30-88)$ & 0.138 \\
Range of motion $\left(^{\circ}\right)$ & & & & 0.081 \\
Forward elevation & $129.83 \pm 23.51(90-160)$ & $125.53 \pm 23.51(80-160)$ & $114.64 \pm 22.40(80-160)$ & 0.451 \\
$\quad$ External rotation on the side & $24.16 \pm 14.54(10-60)$ & $22.12 \pm 10.54(10-60)$ & $20.14 \pm 11.55(10-60)$ & 0.236 \\
Internal rotation at the back & $10.79 \pm 4.54(8-18)$ & $11.59 \pm 4.51(8-18)$ & $11.06 \pm 3.60(8-19)$ & 0.231 \\
Abduction & $87.24 \pm 27.11(40-140)$ & $82.24 \pm 25.10(40-140)$ & $72.86 \pm 26.54(40-130)$ & \\
\hline
\end{tabular}

Values are presented as mean \pm standard deviation (range).

PVAS: pain visual analog scale, FVAS: function visual analog score, ASES: American Shoulder and Elbow Surgeons.

Table 3. Comparison of 6-month postoperative clinical outcomes

\begin{tabular}{lcccc}
\hline Variable & Group I & Group II & Group III & p-value \\
\hline Score & & & & \\
PVAS & $2.09 \pm 2.09(1-6)$ & $1.98 \pm 1.50(1-7)$ & $2.18 \pm 1.91(1-7)$ & 0.761 \\
FVAS & $7.03 \pm 1.55(4-9)$ & $7.56 \pm 1.42(5-9)$ & $7.16 \pm 2.02(4-9)$ & 0.194 \\
ASES & $78.21 \pm 18.51(42-95)$ & $73.37 \pm 18.19(40-88)$ & $70.37 \pm 15.19(40-88)$ & 0.150 \\
Range of motion $\left(^{\circ}\right)$ & & & & \\
Forward elevation & $141.44 \pm 19.97(100-170)$ & $132.68 \pm 19.75(110-170)$ & $135.68 \pm 16.55(100-170)$ & 0.216 \\
External rotation on the side & $34.41 \pm 15.61(20-80)$ & $28.12 \pm 16.30(20-70)$ & $30.12 \pm 16.30(20-70)$ & 0.121 \\
Internal rotation at the back & $8.75 \pm 3.13(4-18)$ & $9.17 \pm 3.42(4-17)$ & $10.17 \pm 4.12(6-17)$ & 0.475 \\
Abduction & $112.48 \pm 28.46(60-170)$ & $105.37 \pm 32.49(50-170)$ & $110.37 \pm 27.49(50-170)$ & 0.232 \\
\hline
\end{tabular}

Values are presented as mean \pm standard deviation (range).

PVAS: pain visual analog scale, FVAS: function visual analog score, ASES: American Shoulder and Elbow Surgeons. 
Table 4. Comparison of 1-year postoperative clinical outcomes

\begin{tabular}{|c|c|c|c|c|}
\hline Variable & Group I & Group II & Group III & $\mathrm{p}$-value \\
\hline \multicolumn{5}{|l|}{ Score } \\
\hline PVAS & $1.14 \pm 1.45(0-4)$ & $1.02 \pm 1.32(0-4)$ & $1.12 \pm 1.02(0-5)$ & 0.638 \\
\hline FVAS & $8.87 \pm 1.16(6-9)$ & $8.90 \pm 1.02(5-9)$ & $8.51 \pm 1.02(5-9)$ & 0.876 \\
\hline ASES & $86.32 \pm 13.46(54-95)$ & $82.70 \pm 12.96(51-88)$ & $81.93 \pm 12.96(52-88)$ & 0.193 \\
\hline \multicolumn{5}{|l|}{ Range of motion $\left(^{\circ}\right)$} \\
\hline Forward elevation & $155.35 \pm 13.52(120-170)$ & $154.07 \pm 15.26(120-170)$ & $152.07 \pm 18.26(120-170)$ & 0.679 \\
\hline External rotation on the side & $49.07 \pm 13.69(30-80)$ & $47.78 \pm 15.53(30-70)$ & $48.18 \pm 15.13(30-70)$ & 0.680 \\
\hline Internal rotation at the back & $7.51 \pm 2.64(4-16)$ & $7.52 \pm 3.02(3-16)$ & $7.22 \pm 2.82(3-16)$ & 0.991 \\
\hline Abduction & $140.23 \pm 28.16(60-170)$ & $146.30 \pm 23.23(50-170)$ & $143.30 \pm 23.23(50-170)$ & 0.312 \\
\hline
\end{tabular}

Values are presented as mean \pm standard deviation (range).

PVAS: pain visual analog scale, FVAS: function visual analog score, ASES: American Shoulder and Elbow Surgeons.

Table 5. Comparison of the number of steroid injections at 3 months postoperative

\begin{tabular}{lcccc}
\hline Steroid injection & Group I $(\mathrm{n}=22)$ & Group II $(\mathrm{n}=21)$ & Group III $(\mathrm{n}=22)$ & $\mathrm{p}$-value \\
\hline Number & 13 & 17 & 19 & 0.011 \\
\hline
\end{tabular}

Table 6. Rate of retear by group

\begin{tabular}{lcccc}
\hline Retear & Group I $(\mathrm{n}=22)$ & Group II $(\mathrm{n}=21)$ & Group III $(\mathrm{n}=22)$ & $\mathrm{p}$-value \\
\hline No. of retear patients $(\%)$ & 0 & $2(9.5)$ & $3(13.6)$ & 0.021
\end{tabular}

\begin{tabular}{|c|c|c|}
\hline Inflammatory phase & Proliferative phase & Remodeling phase \\
\hline $\begin{array}{l}\text { Fibroblast and inflammatory } \\
\text { cells chemotaxis: IGF- } 1 \text {, TGF- } \beta\end{array}$ & $\begin{array}{l}\text { Cell proliferation: } \\
\text { IGF-1, PDGF, TGF- } \beta \text {, bFGF, } \\
\text { BMP-12, -13, - } 14\end{array}$ & ECM remodeling: IGF-1 \\
\hline $\begin{array}{l}\text { Stimulates and regulates } \\
\text { expression of other growth } \\
\text { factors: PDGF }\end{array}$ & $\begin{array}{l}\text { Collagen synthesis and ECM } \\
\text { components: } \\
\text { IGF-1, PDGF, bFGF, TGF- } \beta\end{array}$ & $\begin{array}{l}\text { Termination of cell } \\
\text { proliferation: } \\
\text { TGF- } \beta\end{array}$ \\
\hline $\begin{array}{l}\text { Promotes angiogenesis: } \\
\text { VEGF, bFGF }\end{array}$ & $\begin{array}{l}\text { Cell-matrix interaction: } \\
\text { TGF- } \beta \text {, bFGF }\end{array}$ & $\begin{array}{l}\text { Collagen type I synthesis: } \\
\text { TGF- } \beta \text {, BMP-12, -13, - } 14\end{array}$ \\
\hline
\end{tabular}

Fig. 4. Schematic diagram showing the three-phase process of tendon-to-bone healing. IGF-1: insulin-like growth factor, TGF- $\beta$ : transforming growth factor beta, PDGF: platelet-derived growth factor, VEGF: vascular endothelial growth factor, bFGF: basic fibroblast growth factor, BMP: bone morphogenetic protein, ECM: extracellular matrix.

retear, indicating a significant difference in the healing rate. However, there was no significant difference in clinical and functional results among the three groups.

The prevalence of symptomatic and asymptomatic RCT increases as we age. The pain and functional restrictions of the patients also increase [28]. Although improvement in symptoms can be seen after arthroscopic rotator cuff repair, the healing failure (retear) rate can be as high as $94 \%$ [5,29]. Reducing such retear rates is a challenge for orthopedic surgeons, and several studies are underway $[1,7,8,28,30]$.

A successful RCT repair requires tendon-to-bone healing of the repaired cuff [31]. To date, various approaches have been attempted to improve tendon-to-bone healing processes after rotator cuff repair. Tendon-to-bone healing occurs through a threephase repair process of inflammation, proliferation, and remodeling [32] (Fig. 4). In the final remodeling step, scar tissue is formed, remodeling type III collagen into type I collagen [33]. Application of a type I atelocollagen product to the rotator cuff tendon tear site in a rabbit model improved tendon healing and allowed earlier progression to the remodeling phase, as observed by immunohistochemistry. Histological and biomechanical studies in the rabbit model showed better results in the group that 
used atelocollagen to repair the rotator cuff tendon [7]. In a study by Kim et al. [13], atelocollagen injection on human rotator cuff tendon tear was shown to improve the functional outcome and integrity of the tendon in intra-tendinous RCTs. Therefore, they suggested that type I atelocollagen injection is an optional treatment to delay tear progression and reduce tear size.

Previous investigations have reported that the collagen patch stimulates collagen formation and tissue healing and improves blood vessels, aiding in cuff healing [30,34]. They introduced a bio-inducible collagen patch as a safe and effective treatment for cuff-healing of arthroscopic rotator cuff repair. However, several previously reported studies have cited several weaknesses, such as modeling in animals, small sample size, no control group, or studies involving only partial RCT $[7,13,30]$.

Elevated inflammation can be the cause of ultimate tendon degeneration and inferior tendon tissue quality, resulting in poor tendon-to-bone healing [35]. In the elevated inflammatory condition, tendon-to-bone healing is very difficult at the interface between the tendon and bone. HA acts as a target for the inflammatory and proliferative phases in the three-phase tendon-tobone healing process. The anti-inflammatory effects of $\mathrm{HA}$ accelerate tendon-to-bone healing in rotator cuff repair $[1,36]$. Moreover, HA is thought to play a key role in promoting cell differentiation and growth and can enhance collagen I expression in tendon-derived cells [17]. HA also enhances biomechanical strength in an animal model by increasing chondroid formation and tendon maturation at the tendon-bone interface [8]. Viscosupplementation and elastic properties of $\mathrm{HA}$ also contribute to tendon healing by protecting the repaired cuff.

Several previous studies have shown that various biologic agents such as atelocollagen and HA play an important role in rotator cuff tendon healing $[1,7,8,13,28]$. However, a single biologic agent has limited effects in improving the healing of rotator cuff repair. HA was injected into the repaired rotator cuff in an animal model, and there was no significant difference in biomechanical load to failure between the HA group and control group [37]. Thus, the basic concept used in this study was potential co-administration effect of these biological agents [38]. To date, there has been a limited number of clinical studies evaluating the effects of co-administration of a combined biologic in repaired rotator cuff tendon.

One of the strengths of our study was its randomized and blinded design. This study is the first clinical trial to investigate the effect of combined application of atelocollagen and HA on the healing of human repaired rotator cuff tendon. Further, all surgeries were performed by a single surgeon owing to the relatively small number of patients. We used MRI images in all pa- tients to accurately assess the integrity of repaired tendon. Finally, we studied the same surgical technique and only those patients who complete repair (type I) of the greater tuberosity footprint.

This study had several limitations. First, this study has structural weakness. Since there is no group using only atelocollagen, it is difficult to rule out the effect of atelocollagen on cuff healing. Further study is needed of only an atelocollagen group. Second, the mean follow-up period was short. Therefore, further research with long-term follow-up of a minimum period of 2 years is needed. Third, the sample size was relatively small. We did not include patients who did not undergo complete repair due to large-sized tears. Finally, in this study, histological analysis of the healed cuff was not performed. The histological structure of the repaired tendon-to-bone interface is different from that of normal tendon insertion [39]; therefore, further studies including histological analysis between groups are needed.

Co-administration of atelocollagen and HA improved healing of the rotator cuff and increased the integrity of the rotator cuff repair site. This study provides encouraging evidence for use of combined atelocollagen-HA injections in treatment of patients with full-thickness RCT.

\section{ORCID}

Jeung Yeol Jeong https://orcid.org/0000-0001-8145-1302

Eun Kyung Khil https://orcid.org/0000-0002-7764-4344 Tae Soung Kim https://orcid.org/0000-0002-7904-8861 Young Woo Kim https://orcid.org/0000-0001-5907-3720

\section{REFERENCES}

1. Li H, Chen Y, Chen S. Enhancement of rotator cuff tendon-bone healing using bone marrow-stimulating technique along with hyaluronic acid. J Orthop Translat 2019;17:96-102.

2. Minagawa H, Yamamoto N, Abe H, et al. Prevalence of symptomatic and asymptomatic rotator cuff tears in the general population: from mass-screening in one village. J Orthop 2013; $10: 8-12$

3. Cho NS, Moon SC, Jeon JW, Rhee YG. The influence of diabetes mellitus on clinical and structural outcomes after arthroscopic rotator cuff repair. Am J Sports Med 2015;43:991-7.

4. Park JS, Park HJ, Kim SH, Oh JH. Prognostic factors affecting rotator cuff healing after arthroscopic repair in small to medium-sized tears. Am J Sports Med 2015;43:2386-92.

5. Sugaya H, Maeda K, Matsuki K, Moriishi J. Repair integrity and functional outcome after arthroscopic double-row rotator cuff repair: a prospective outcome study. J Bone Joint Surg Am 
2007;89:953-60.

6. Im GI, Ahn JH, Kim SY, Choi BS, Lee SW. A hyaluronate-atelocollagen/beta-tricalcium phosphate-hydroxyapatite biphasic scaffold for the repair of osteochondral defects: a porcine study. Tissue Eng Part A 2010;16:1189-200.

7. Suh DS, Lee JK, Yoo JC, et al. Atelocollagen enhances the healing of rotator cuff tendon in rabbit model. Am J Sports Med 2017;45:2019-27.

8. Honda H, Gotoh M, Kanazawa T, et al. Hyaluronic acid accelerates tendon-to-bone healing after rotator cuff repair. Am J Sports Med 2017;45:3322-30.

9. Mazzocca AD, McCarthy MB, Chowaniec DM, et al. The positive effects of different platelet-rich plasma methods on human muscle, bone, and tendon cells. Am J Sports Med 2012;40: 1742-9.

10. Prockop DJ, Kivirikko KI. Collagens: molecular biology, diseases, and potentials for therapy. Annu Rev Biochem 1995;64:40334.

11. Pins GD, Christiansen DL, Patel R, Silver FH. Self-assembly of collagen fibers: influence of fibrillar alignment and decorin on mechanical properties. Biophys J 1997;73:2164-72.

12. Lynn AK, Yannas IV, Bonfield W. Antigenicity and immunogenicity of collagen. J Biomed Mater Res B Appl Biomater 2004;71:343-54.

13. Kim JH, Kim DJ, Lee HJ, Kim BK, Kim YS. Atelocollagen injection improves tendon integrity in partial-thickness rotator cuff tears: a prospective comparative study. Orthop J Sports Med 2020;8:2325967120904012.

14. Mitsui Y, Gotoh M, Nakama K, Yamada T, Higuchi F, Nagata K. Hyaluronic acid inhibits mRNA expression of proinflammatory cytokines and cyclooxygenase-2/prostaglandin $\mathrm{E}(2)$ production via CD44 in interleukin-1-stimulated subacromial synovial fibroblasts from patients with rotator cuff disease. J Orthop Res 2008;26:1032-7.

15. Hays PL, Kawamura S, Deng XH, et al. The role of macrophages in early healing of a tendon graft in a bone tunnel. J Bone Joint Surg Am 2008;90:565-79.

16. Manferdini C, Guarino V, Zini N, et al. Mineralization behavior with mesenchymal stromal cells in a biomimetic hyaluronic acid-based scaffold. Biomaterials 2010;31:3986-96.

17. Osti L, Berardocco M, di Giacomo V, Di Bernardo G, Oliva F, Berardi AC. Hyaluronic acid increases tendon derived cell viability and collagen type I expression in vitro: comparative study of four different Hyaluronic acid preparations by molecular weight. BMC Musculoskelet Disord 2015;16:284.

18. Chou WY, Ko JY, Wang FS, et al. Effect of sodium hyaluronate treatment on rotator cuff lesions without complete tears: a ran- domized, double-blind, placebo-controlled study. J Shoulder Elbow Surg 2010;19:557-63.

19. Zhao J, Huang H, Liang G, Zeng LF, Yang W, Liu J. Effects and safety of the combination of platelet-rich plasma (PRP) and hyaluronic acid (HA) in the treatment of knee osteoarthritis: a systematic review and meta-analysis. BMC Musculoskelet Disord 2020;21:224.

20. Cunningham G, Lädermann A, Denard PJ, Kherad O, Burkhart SS. Correlation between American shoulder and elbow surgeons and single assessment numerical evaluation score after rotator cuff or SLAP repair. Arthroscopy 2015;31:1688-92.

21. Yoo JC, Ahn JH, Yang JH, Koh KH, Choi SH, Yoon YC. Correlation of arthroscopic repairability of large to massive rotator cuff tears with preoperative magnetic resonance imaging scans. Arthroscopy 2009;25:573-82.

22. Kim KC, Shin HD, Lee WY. Repair integrity and functional outcomes after arthroscopic suture-bridge rotator cuff repair. J Bone Joint Surg Am 2012;94:e48.

23. Oh JH, Oh CH, Choi JA, Kim SH, Kim JH, Yoon JP. Comparison of glenohumeral and subacromial steroid injection in primary frozen shoulder: a prospective, randomized short-term comparison study. J Shoulder Elbow Surg 2011;20:1034-40.

24. Sugaya H, Maeda K, Matsuki K, Moriishi J. Functional and structural outcome after arthroscopic full-thickness rotator cuff repair: single-row versus dual-row fixation. Arthroscopy 2005; 21:1307-16.

25. Park MC, Tibone JE, ElAttrache NS, Ahmad CS, Jun BJ, Lee TQ. Part II: biomechanical assessment for a footprint-restoring transosseous-equivalent rotator cuff repair technique compared with a double-row repair technique. J Shoulder Elbow Surg 2007;16:469-76.

26. Kaizawa Y, Leyden J, Behn AW, et al. Human tendon-derived collagen hydrogel significantly improves biomechanical properties of the tendon-bone interface in a chronic rotator cuff injury model. J Hand Surg Am 2019;44:899.e1-11.

27. Shrout PE, Fleiss JL. Intraclass correlations: uses in assessing rater reliability. Psychol Bull 1979;86:420-8.

28. Walsh MR, Nelson BJ, Braman JP, et al. Platelet-rich plasma in fibrin matrix to augment rotator cuff repair: a prospective, single-blinded, randomized study with 2-year follow-up. J Shoulder Elbow Surg 2018;27:1553-63.

29. Atesok K, Fu FH, Wolf MR, et al. Augmentation of tendon-tobone healing. J Bone Joint Surg Am 2014;96:513-21.

30. Thon SG, O’Malley L 2nd, O’Brien MJ, Savoie FH 3rd. Evaluation of healing rates and safety with a bioinductive collagen patch for large and massive rotator cuff tears: 2-year safety and clinical outcomes. Am J Sports Med 2019;47:1901-8. 
31. Boileau P, Brassart N, Watkinson DJ, Carles M, Hatzidakis AM, Krishnan SG. Arthroscopic repair of full-thickness tears of the supraspinatus: does the tendon really heal. J Bone Joint Surg Am 2005;87:1229-40.

32. Kawamura S, Ying L, Kim HJ, Dynybil C, Rodeo SA. Macrophages accumulate in the early phase of tendon-bone healing. J Orthop Res 2005;23:1425-32.

33. Weeks KD 3rd, Dines JS, Rodeo SA, Bedi A. The basic science behind biologic augmentation of tendon-bone healing: a scientific review. Instr Course Lect 2014;63:443-50.

34. Schlegel TF, Abrams JS, Bushnell BD, Brock JL, Ho CP. Radiologic and clinical evaluation of a bioabsorbable collagen implant to treat partial-thickness tears: a prospective multicenter study. J Shoulder Elbow Surg 2018;27:242-51.

35. Kovacevic D, Rodeo SA. Biological augmentation of rotator cuff tendon repair. Clin Orthop Relat Res 2008;466:622-33.
36. Li H, Ge Y, Zhang P, Wu L, Chen S. The effect of layer-by-layer chitosan-hyaluronic acid coating on graft-to-bone healing of a poly(ethylene terephthalate) artificial ligament. J Biomater Sci Polym Ed 2012;23:425-38.

37. Nakamura H, Gotoh M, Kanazawa T, et al. Effects of corticosteroids and hyaluronic acid on torn rotator cuff tendons in vitro and in rats. J Orthop Res 2015;33:1523-30.

38. Lee MI, Kim JH, Kwak HH, et al. A placebo-controlled study comparing the efficacy of intra-articular injections of hyaluronic acid and a novel hyaluronic acid-platelet-rich plasma conjugate in a canine model of osteoarthritis. J Orthop Surg Res 2019;14:314.

39. Kanazawa T, Gotoh M, Ohta K, et al. Histomorphometric and ultrastructural analysis of the tendon-bone interface after rotator cuff repair in a rat model. Sci Rep 2016;6:33800. 